\title{
Promiscuous Targets for Antitubercular Drug Discovery: The Paradigm of DprE1 and MmpL3
}

\author{
Giulia Degiacomi ${ }^{1,+}{ }^{+}$Juan Manuel Belardinelli ${ }^{2,+} \mathbb{C}$, Maria Rosalia Pasca ${ }^{1} \mathbb{D}$, Edda De Rossi ${ }^{1}$, \\ Giovanna Riccardi ${ }^{1, *}$ and Laurent Roberto Chiarelli ${ }^{1, * \mathbb{D}}$ \\ 1 Department of Biology and Biotechnology "Lazzaro Spallanzani", University of Pavia, 27100 Pavia, Italy; \\ giulia.degiacomi@unipv.it (G.D.); mariarosalia.pasca@unipv.it (M.R.P.); edda.derossi@unipv.it (E.D.R.) \\ 2 Mycobacteria Research Laboratories, Department of Microbiology, Immunology and Pathology, \\ Colorado State University, Fort Collins, CO 80523-1682, USA; juan.belardinelli@colostate.edu \\ * Correspondence: giovanna.riccardi@unipv.it (G.R.); laurent.chiarelli@unipv.it (L.R.C.); \\ Tel.: +39-382-985574 (G.R.); +39-382-987241 (L.R.C.) \\ + These authors contributed equally to this work.
}

Received: 18 December 2019; Accepted: 11 January 2020; Published: 15 January 2020

check for updates

\begin{abstract}
The development and spread of Mycobacterium tuberculosis multi-drug resistant strains still represent a great global health threat, leading to an urgent need for novel anti-tuberculosis drugs. Indeed, in the last years, several efforts have been made in this direction, through a number of high-throughput screenings campaigns, which allowed for the identification of numerous hit compounds and novel targets. Interestingly, several independent screening assays identified the same proteins as the target of different compounds, and for this reason, they were named "promiscuous" targets. These proteins include DprE1, MmpL3, QcrB and Psk13, and are involved in the key pathway for M. tuberculosis survival, thus they should represent an Achilles' heel which could be exploited for the development of novel effective drugs. Indeed, among the last molecules which entered clinical trials, four inhibit a promiscuous target. Within this review, the two most promising promiscuous targets, the oxidoreductase DprE1 involved in arabinogalactan synthesis and the mycolic acid transporter MmpL3 are discussed, along with the latest advancements in the development of novel inhibitors with anti-tubercular activity.
\end{abstract}

Keywords: mycobacteria; tuberculosis; multi-drug resistance; drug discovery; promiscuous targets

\section{The Added Value of Promiscuous Targets for Antitubercular Drug Discovery}

One of the biggest problems in fighting Mycobacterium tuberculosis (Mtb), the etiologic agent of tuberculosis (TB), is the development and spread of multi-drug resistant strains [1]. Therefore, there is an urgent need to identify novel druggable targets for the development of more efficient anti-TB agents $[2,3]$. In this context, the medicinal chemistry efforts made in the last years led to the discovery of new antimycobacterial compounds, and the identification of novel targets [3-5].

High-throughput screenings (HTS), based on Mtb whole cells, were developed to identify hit compounds with potent inhibitory activity, and consequently, new targets emerged. The HTS had the merit of fueling the scarce TB drug development pipeline, since many molecules under preclinical and clinical development came out from this approach. Indeed, the first new TB drug, Bedaquiline, approved by the Food and Drug Administration (FDA) since 1971, was discovered in a whole-cell HTS campaign [6], and the same origin had both Delamanid [7] and Pretomanid [8], other two drugs recently approved for multidrug resistant tuberculosis (MDR-TB) and extensively drug-resistant tuberculosis (XDR-TB) treatment $[9,10]$. 
Curiously, an unforeseen outcome of many phenotypic screens against Mtb is the finding that the same targets have been frequently found in many different screening assays, despite the use of different compound libraries [11]. These targets were named "promiscuous" targets, for their nonspecific susceptibility to being inhibited by different scaffolds [2,12]. Although this term was initially given with a negative connotation, the value of these potential pharmacological targets has been reevaluated. Indeed, the high vulnerability of these essential targets, reflecting the biggest vulnerabilities of Mtb, can provide new opportunities to be explored for the development of TB drugs [12]. Among them, there are DprE1, MmpL3, QcrB and Psk13 [3,13].

DprE1 is an enzyme that works in concert with DprE2 to synthesize the unique arabinose precursor for lipoarabinomannan and arabinogalactan, essential building blocks of the mycobacterial cell-wall [14]. To date, more than 15 pharmacophores were found to inhibit DprE1 activity.

MmpL3 is the only Mtb transporter of trehalose monomycolate, required for the formation of the mycolic acid layer of the cell wall [15], and has been found to be affected by several molecules. Recently, direct inhibition of MmpL3 by BM212, the first compound found to hit MmpL3, was shown using spheroplasts [15], while the dissipation of proton motive force is the proposed mechanism for the other molecules [16].

QcrB encodes the $b$ subunit of ubiquinol cytochrome $C$ reductase, involved in the electron transport. Among the other compounds, Q203 is a promising clinical candidate, which blocks Mtb cell growth by targeting the respiratory cytochrome bc1 complex [17,18].

Finally, polyketide synthase Psk13, essential for the formation of the mycolic acid precursors, has been targeted by thiophenes and benzofuran containing molecules $[19,20]$.

It is noteworthy that several research groups independently identified these promiscuous targets. These proteins are embedded in pathways that have key roles for Mtb growth and survival under the screening conditions, but even more important during infection. Their essentiality represents an $\mathrm{Mtb}$ Achilles' heel that is important to exploit for the development of new effective drug regimens able to shorten the TB treatment. Interestingly, all these promiscuous targets are localized within the cell envelope, emphasizing that the cell wall still represents a fruitful source of drug targets.

In recent years, several innovative strategies have been implemented to avoid the rediscovery of promiscuous targets [17,21-23]. Nevertheless, it is noteworthy that promiscuous targets proved to be successful in medicinal chemistry: four inhibitors Q203 (QcrB), SQ-109 (MmpL3), Macozinone (MCZ) and TBA-7371 (DprE1) entered clinical trials [24-29]. Thus, in parallel, a rational exploitation of already available promiscuous targets could lead to optimized scaffolds that retain the ability to attack the most vulnerable weakness of tubercle bacilli.

\section{The First Discovery of DprE1 and MmpL3 as Drug Target}

Dr. Vadim Makarov and collaborators, including our Laboratory, published in 2009 the first report in which DprE1 was described as the target of 1,3-benzothiazin-4-ones (BTZ), a new class of agents endowed with antimycobacterial activity [30]. To find the BTZ target, two genetic approaches were performed in parallel using both a Mycobacterium smegmatis cosmid library for resistance to BTZ, and the selection and characterization of M. smegmatis, Mycobacterium bovis BCG and M. tuberculosis spontaneous resistant mutants. Both methods revealed that $d p r E 1$ gene was responsible for BTZ resistance. It is noteworthy that all the mutants carried mutations in the same codon of $d p r E 1$, leading to the replacement of Cys387 with a Ser or Gly residue [30]. DprE1 was known to be involved in the arabinogalactan biosynthesis, a key precursor required for the synthesis of the cell-wall [14,31], and it was demonstrated that its inhibition abolishes the formation of decaprenylphosphoryl arabinose (DPA), thus provoking cell lysis and bacterial death [30]. Later, new antimycobacterial compounds targeting DprE1 were identified by independent whole cell-based screens, like dinitrobenzamides (DNB) and bromoquinoxaline (VI-9376) [32,33], and afterward, numerous DprE1 inhibitors have come out since that groundbreaking report in 2009. 
In this context, it has been demonstrated that DprE1 is essential for mycobacterial cell growth and survival [34,35]. Moreover, using M. tuberculosis conditional knockdown mutants, it has been shown that depletion of the DprE1 mRNA and protein level leads to a rapid cell death in vitro and ex vivo, suggesting that some enzymatic reactions are more sensitive to inhibition [35], providing the proof-of-principle of why it is so successful hitting DprE1 enzyme.

MmpL3 was firstly identified in our laboratory as the cellular target of BM212, the hit compound of a pyrrole-derivative class of antimycobacterial agents by screening the M. smegmatis cosmid library for BM212 resistance, as well as the selection and characterization of spontaneous resistant mutants [36]. MmpL3 is a transporter belonging to the mycobacterial membrane protein large (MmpL) family, specific for Actinobacteria. Since MmpL3 protein belongs to the resistance-nodulation-cell division (RND) permease superfamily, involved mainly in drug efflux, there was concern that the BM212 resistance could have been due to an enhanced efflux of the drug. Using efflux pump inhibitors, the authors provided evidence that mutations in $m m p L 3$ gene were instead responsible for resistance to BM212 per se and did not mediate resistance to BM212 via drug efflux [36]. Moreover, M. smegmatis spheroplasts assay showed that BM212 inhibits the MmpL3 transport activity, corroborating the evidence that MmpL3 was the BM212 cellular target [15].

Immediately after this first publication, MmpL3 was demonstrated to be the target of SQ109, an antitubercular in clinical trials, for which the mechanism of action was still unclear, and adamantyl urea AU1235, a compound displaying potent bactericidal activity against Mtb [37,38]. Genetic and biochemical studies indicated a clear effect of inhibiting MmpL3 on the translocation of trehalose monomycolate (TMM) in Mtb, thus abolishing the trehalose dimycolate (TDM) formation and mycolic acid transfer onto arabinogalactan $[37,38]$. Subsequently, several papers have reported the discovery of new MmpL3 inhibitors.

MmpL3 is essential for both mycobacterial growth and intracellular survival [16,39]. Strikingly, its broad promiscuity can be explained not only for its essentiality for tubercle bacilli, but also because the proton motive force needed to TMM transport across the membrane is dissipated by different MmpL3 inhibitors [16], a possible indirect mechanism.

The importance of these promiscuous targets can be exemplified by the numerous papers that report novel compound(s) able to exert antimycobacterial activity targeting these proteins, but the presence of drug candidates in the antitubercular pipeline better highlight the relevance of promiscuous targets. Indeed, among the new drug candidates, Macozinone (MCZ), BTZ-043 and TBA-7371 (or AZ 7371), present in Phase I or II, inhibit DprE1, while SQ109, hitting MmpL3, has completed Phase IIb study. Moreover, the Phase IIa of telacebec (Q203) has given positive results: telacebec has a high specificity for the cytochrome bc1 complex of $\mathrm{Mtb}$, particularly for QcrB, another promiscuous target.

\section{DprE1: The Hot TB Target of the Moment}

\subsection{Why DprE1 Is a Promiscuous Target}

DprE1 (Decaprenylphosphoryl- $\beta$-D-ribofuranose 2-oxidoreductase, EC 1.1.98.3), is involved along with DprE2 (Decaprenylphosphoryl-2-keto- $\beta$-D-erythro-pentose reductase, EC 1.1.1.333), in the two-step epimerization of decaprenylphosphoribose (DPR) to decaprenylphosphoarabinose (DPA), a key arabinosyl donor essential for the biosynthesis of cell-wall arabinan polymers [40].

As a flavoprotein, after the first half-reaction in which DPR is oxidized into decaprenylphosphorylerythropentose (DPX), DprE1 needs to reoxidize the reduced flavin to begin a new catalytic cycle, thus, to complete this half-reaction the enzyme must use an electron acceptor. Initially, DprE1 was considered an oxidase, which uses molecular oxygen as an electron acceptor [41]. However, the enzyme was found to utilize more efficiently organic compounds, including bacterial membrane-embedded quinones, such as menaquinone, which was postulated as a physiological electron acceptor [41]. For this reason, the enzyme should be more precisely defined as an oxidoreductase. 
In this context, DprE1 was found to have a very broad specificity for the electron acceptor, being able to use several compounds belonging to very different chemical classes. Indeed, the enzyme can reduce not only quinones, but also indophenols such as 2,6-dichlorophenolindophenol, or the phenoxazine moiety of resazurin, both compounds used in DprE1 activity assays [41,42], as well as different nitroaromatic moieties that characterize several covalent inhibitors of this enzyme [30,32,33,43,44].

To date, more than 15 chemical classes of compounds inhibiting DprE1 have been reported. These classes encompass both covalent and noncovalent inhibitors, and although the covalent ones are the most successful, several noncovalent inhibitors with significant antitubercular activity have actually been described $[45,46]$.

The success of DprE1 covalent inhibitors in antitubercular drug discovery partly resides in this peculiar reactivity of the enzyme with the nitroaromatic moiety. Indeed, the most potent class of these inhibitors, the benzothiazinones, has been demonstrated to be suicide prodrugs that need activation to covalently bind DprE1 [47]. This activation consists of the reduction of the nitro group to nitroso, which rapidly forms a semimercaptal covalent adduct with a cysteine residue, located in a pocket just in front of the flavin cofactor. In this way, since the electron acceptor site is occupied, the enzyme is unable to reoxidize the flavin cofactor, resulting in being irreversibly inhibited [41,48] (Figure 1).

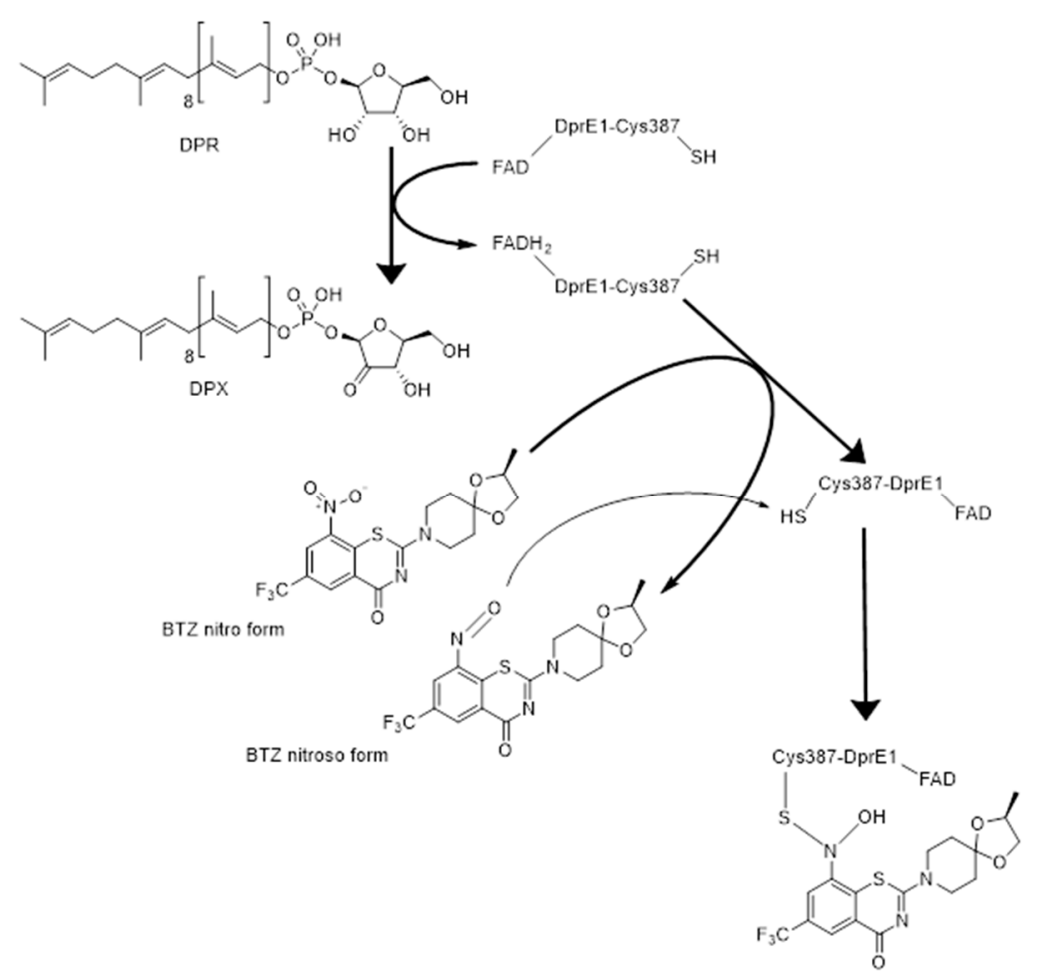

Figure 1. Mechanism of activation of the BTZ043 suicide inhibitor of DprE1.

This mechanism of action has been demonstrated for benzothiazinones and benzothiazinone analogs $[41,43,49,50]$. However, other different classes of nitro-compounds have been identified as potent DprE1 inhibitors, including dinitrobenzamides [32], nitroquinoxalines [33] and nitroimidazoles [51], that conceivably share the same mechanism of action of benzothiazinones [52].

Currently, 33 DprE1 structures from M. tuberculosis or M. smegmatis have been deposited in the Protein Data Bank, as apoenzyme $[41,53]$ or in complex with both covalent $[41,43,44,49,54]$ and noncovalent inhibitors [43,50,55-58]. The enzyme is characterized by the two-domain topology of the vanillyl-alcohol oxidase family of oxidoreductases, which includes a flavin adenine dinucleotide (FAD)-binding domain and the substrate-binding domain [41]. The isoalloxazine ring of FAD is located at the interface of the substrate-binding domain and the cofactor-binding domain, where are located in 
two disordered loops, which have been supposed to be involved in interactions with the DPR substrate, or with other proteins involved in the DPA biosynthesis [42].

In all structures of DprE1 in complex with inhibitors, all molecules showed binding sites that are significantly overlapped (Figure 2). This binding pocket, which conceivably constitutes the binding site of the physiological electron acceptor of DprE1, shows a very broad specificity, thus explaining the promiscuity of DprE1 for inhibitors.

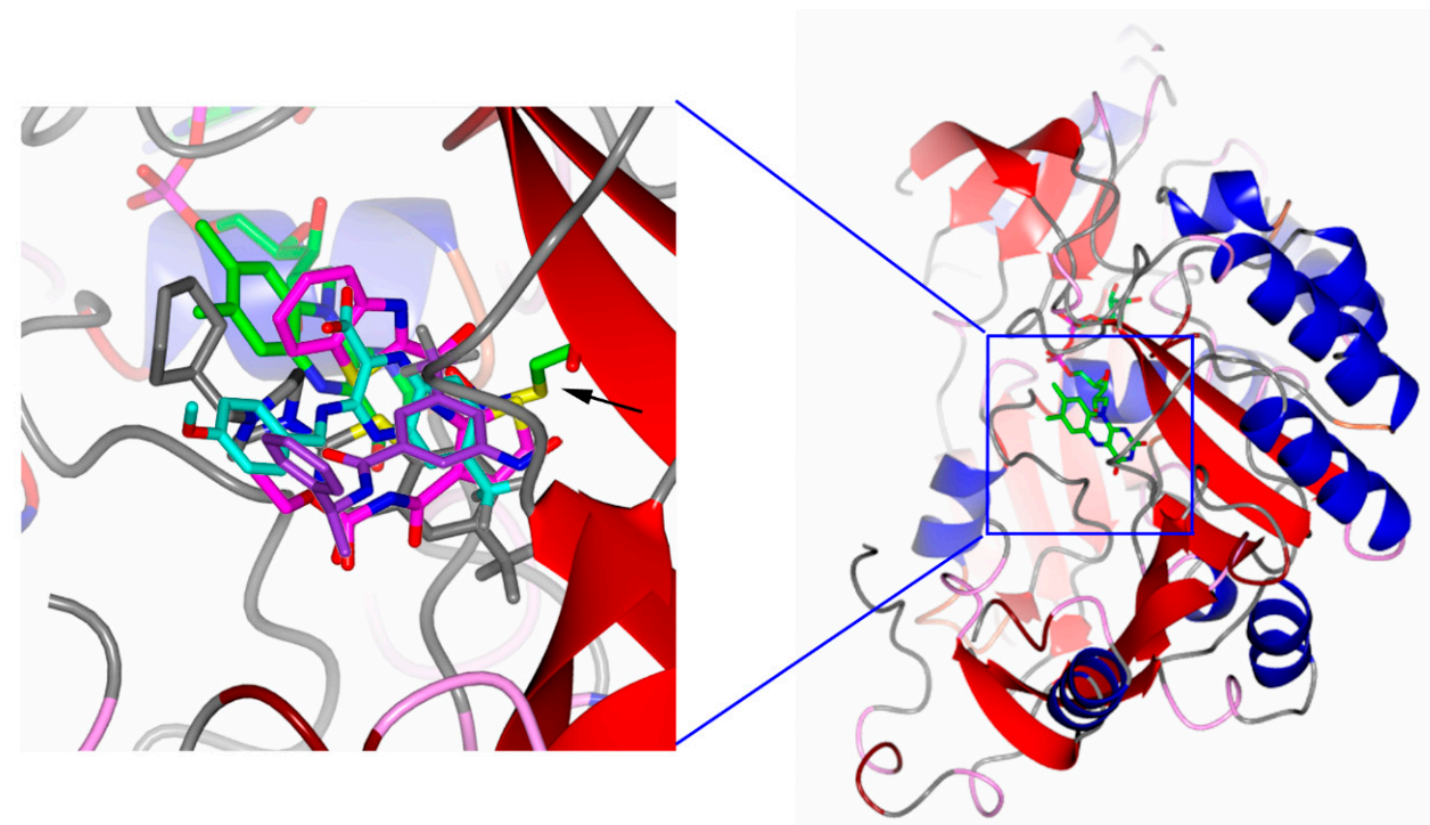

Figure 2. Crystal structure of Mycobacterium tuberculosis (Mtb) DprE1 and detail of the inhibitor binding sites. The superimposition of the structures of DprE1, cocrystallized with both covalent and noncovalent inhibitors (PBTZ-169, PDB: 4NCR [49] with carbon atoms in grey; Ty38c, PDB: 4P8K [58] with carbon atoms in cyan; TCA1, PDB: 4KWS [55] with carbon atoms in magenta; CT325, PDB: 4FF6 [43] with carbon atoms in violet), shows how the compounds have significantly overlapping binding sites, located in front of the isoalloxazine ring of the FAD cofactor (with carbon atoms in green). The black arrow points to the Cys387 side chain.

A broad specificity for inhibitors is a necessary but not sufficient condition for a target, to be considered promiscuous. Indeed, as promiscuous targets usually emerge during phenotypic screening, this implies that the inhibitors identified have antitubercular activity, so they can reach the cellular compartment in which the target resides. It is noteworthy that among the obstacles for the antitubercular drug discovery process, there is the difficulty of the compounds to cross the cell wall and the cellular membranes. Moreover, the presence of efflux pumps that can extrude the compounds outside the cells, and potential cytosolic inactivation processes of drugs lead to a lack of activity. In this context, it is noteworthy that one of the most successful pathways for antitubercular discovery is the cell wall compartment [59].

Recently, it was demonstrated that DPA biosynthesis partly occurs also outside the cytosolic membrane, and in particular, DprE1 was localized into the periplasm [60]. How DprE1 can reach the periplasmic compartment is still not clear, despite this protein, as well as its partner DprE2, do not possess any export signal for the translocation across the cytosolic membrane [60]. Anyhow, this localization allows drugs against DprE1 not only to easily reach the target, but also to escape several resistance mechanisms such as efflux pump or potential cytoplasmic inactivating enzymes. 


\subsection{DprE1 Inhibitors, Which Are the Current Status and Future Perspectives}

Currently, at least 11 different scaffolds have been reported as effective DprE1 inhibitors, either covalent and noncovalent, showing different efficacy in vitro, ex vivo and in vivo [46]. It is noteworthy that the majority of these compounds have been identified through phenotypic screening, then subjected to optimization processes. The most representative compounds are reported in Table 1.

Table 1. Main covalent and not covalent DprE1 inhibitors showing antitubercular activity.

\begin{tabular}{|c|c|c|c|c|}
\hline Chemical Class & Compound & Structure & M. tuberculosis MIC & Ref. \\
\hline \multicolumn{5}{|c|}{ Covalent inhibitors } \\
\hline \multirow{2}{*}{ Benzothiazinones } & BTZ043 & & $0.0023 \mu \mathrm{M}$ & [30] \\
\hline & PBTZ169 & & $0.001 \mu \mathrm{M}$ & [49] \\
\hline Dinitrobenzamides & DNB1 & & $0.69 \mu \mathrm{M}$ & [32] \\
\hline Nitro-quinoxalines & VI-9376 & & $3.1 \mu \mathrm{M}$ & [33] \\
\hline Triazoles & 377790 & & $0.48 \mu \mathrm{M}$ & [51] \\
\hline & & nt inhib & & \\
\hline & TCA1 & & $0.51 \mu \mathrm{M}$ & [55] \\
\hline & $7 a$ & & $0.08 \mu \mathrm{M}$ & [61] \\
\hline Thiadiazoles & GSK-710 & & $4 \mu \mathrm{M}$ & [42] \\
\hline Carboxy-quinoxalines & Ty38c & & $3.1 \mu \mathrm{M}$ & [58] \\
\hline Aminoquinolones & 3 & & $0.8 \mu \mathrm{M}$ & [62] \\
\hline
\end{tabular}


Table 1. Cont.

\begin{tabular}{lclll}
\hline Chemical Class & Compound & M. tuberculosis MIC & Ref. \\
\hline Pyrazolopyridones & 19 & & \\
Azaindoles & TBA-7371 & & \\
\hline
\end{tabular}

The first DprE1 inhibitors identified is the BTZ043, belonging to the class of the benzothiazinones [30]. Moreover, nearly in the same period other classes of compounds, such as dinitrobenzamides, nitroquinoxaline and triazoles, have been described as covalent inhibitors [32,33,51].

As above reported, all these compounds possess a nitro group, that is converted to nitroso through the oxidation of the $\mathrm{FADH}_{2}$ cofactor of DprE1, allowing the formation of a covalent bond with a cysteine residue. However, an alternative and similarly probable mechanism of formation of the nitroso group has been proposed. In this model, the thiol group of the cysteine is able to start the redox reaction which converts the nitro group into nitroso similarly to the von Richter reaction [65].

Despite BTZ043 was extremely potent against $M$. tuberculosis with an MIC of $1 \mathrm{ng} / \mathrm{mL}$ ( $2.3 \mathrm{nM}$ ) [30], its great efficacy was not translated into a mouse model, probably due to its relatively high lipophilicity, and low pharmacokinetic properties. Several attempts were then done to improve this class of compounds, and in particular, a structure activity relationship (SAR) study of piperazine benzothiazinone derivatives afforded the PBTZ-169 [49]. This compound, bearing a cyclohexylmethyl substituted piperazine showed improved in vitro and in vivo potency, and resulted in being less susceptible to the attack of nitroreductases [66]. PBTZ-169 is currently in a clinical trial under the name macozinone (MCZ) [29].

Although the nitro group is essential for the activity of the benzothiazinones [30,66], although potentially mutagenic, several attempts to substitute it, for instance by a pyrrole ring, or by an azide group were performed $[67,68]$. However, all these attempts led to noncovalent inhibitors, with much-reduced efficacy.

Also, noncovalent inhibitors, although less potent in vitro, can show in-vivo efficacy. For instance, the first discovered noncovalent inhibitor was the benzothiazole TCA1. This compound showed a relatively high MIC against $M$. tuberculosis of $0.5 \mu \mathrm{M}$, nevertheless, it proved to be effective in mice, both in acute and chronic infection models [55]. A series of pyrimidine conjugate of the benzothiazole give a further improvement of this compound, with the best derivatives showing MIC of 0.08-0.09 $\mu \mathrm{M}$ [61]. More recently a new class of inhibiting DprE1 benzothiazoles, benzothiazole-N-oxides, have been identified through a whole cells screening [44], but despite their promising bactericidal activity they showed toxicity issues.

The high vulnerability of DprE1 as an antitubercular drug target was confirmed by the number of screening campaigns that identified effective noncovalent inhibitors, including thiadiazoles [42], carboxy-quinoxalines [58], aminoquinolones [62], pyrazolopyridones [63], and azaindoles [69,70].

The latter are the most promising drug candidates among the noncovalent DprE1 inhibitors, the best inhibitor showing potent antitubercular activity in vitro and in in vivo chronic infection models, low toxicity and no antagonistic activity with other TB drugs [64]. Currently, the azaindole TBA-7371 has started phase I clinical trials [27], further confirming the great potential of DprE1 inhibitors in anti-tubercular drug discovery. 


\subsection{DprE2: A Promising Target for Future Drug Discovery}

As above reported, the conversion of DPR to DPA is a two steps reaction, in which the product of DprE1 decaprenyl-phospho-2'-keto-D-arabinose must be reduced to finalize the epimerization of the substrate. This second step is catalyzed by the enzyme DprE2 (decaprenylphosphoryl-2-keto- $\beta$-D-erythro-pentose reductase) [14]. As DprE1, also DprE2 is essential for mycobacterial growth [35]. Moreover, the two enzymes have been supposed to strongly interact, and sometimes they were considered two subunits of a single enzyme named decaprenylphosphoryl- $\beta$-D-ribofuranose 2-epimerase. Indeed, DprE1 and DprE2 interaction in Corynebacterium glutamicum, strongly related to mycobacteria, have been demonstrated by a bacterial two-hybrid system [71]. An in silico study using homology modeling, protein threading and molecular dynamics proposed a model in which DprE1 and DprE2 form a complex [72], but currently, no structural and functional data on DprE2 have been reported yet. Anyhow, to fulfill their reactions it is conceivable that the two enzymes must work in concert, thus, reasonably a strong interaction occurs. In this context, the elucidation of the structural and functional behavior of the full decaprenylphosphoryl- $\beta$-D-ribofuranose 2-epimerase complex should be a useful tool for the development of further antitubercular inhibitors [73].

\section{Mmp13 Transporter: The Other Hot TB Target of the Moment}

\subsection{MmpL3: A Mycolic Acid Transporter}

MmpL3 is a membrane protein, member of the resistance-nodulation-cell division (RND) superfamily of transporters. In mycobacteria, MmpL transporters have specialized in the export of several lipids and glycolipids across the plasma membrane to the cell surface, namely, trehalose monomycolates (TMM), di- and poly-acyltrehaloses, sulfolipids, phthiocerol dimycocerosates, monomycolyldiacylglycerol, glycopeptidolipids and mycobactins [38,74-78]. Genetic studies with transposon mutant libraries and the inability to knock-out the gene using different strategies suggested that MmpL3 was essential for the survival of M. tuberculosis [38,79]. An alternative strategy, utilizing knock-down strains both in vitro and in vivo had confirmed that MmpL3 is indeed essential for survival. Silencing of MmpL3 in mice, both during the acute or persistence phase of infection, led to a complete clearance of bacteria from lungs and spleens. These studies not only reinforce the idea of MmpL3 as an attractive drug target but also the potential of MmpL3 inhibitors to shorten TB treatment [80].

MmpL3 contains 12 transmembrane segments with two periplasmic loops and one C-terminal cytoplasmic domain. The periplasmic loops are essential for the MmpL3 function and are involved in substrate binding. On the other hand, the cytoplasmic loop, which is only present in MmpL3 and MmpL11 but not in other members of the MmpL family, is not essential for MmpL3 transport activity [81]. The exact role of the C-terminal domain is still not clear but it has been proposed to act as a signal for polar localization of the protein, since its removal caused MmpL3 to be more diffuse across the cells in contrast to the typical subpolar localization of the full protein [82]. In addition to that, this domain was shown to be involved in protein-protein interactions with itself as well as with other proteins, pointing to a role in oligomerization and/or coordination of synthesis of other cell wall components [83]. MmpL3 transports TMM across the cell membrane to the periplasmic space where it serves as a mycolic acid donor to another TMM molecule to form TDM, or to arabinogalactan as part of the mAGP core. Both of these reactions are catalyzed by the Ag85 family of enzymes. Mycolic acids are essential components of the mycobacterial cell wall and its biosynthesis has been shown as an effective drug target in mycobacteria, with several antibiotics targeting this pathway. The best example of this is isoniazid, which inhibits the FASII enoyl-ACP reductase InhA, and is one of the pillars in tuberculosis treatment [84].

MmpL3 relies on the proton motive force as an energy source to drive TMM transport. Thus, the flux of protons across the transmembrane region of MmpL3 would drive the conformational 
changes necessary for the translocation of TMM. This is evidenced by mutagenesis studies showing that charged residues lying on the transmembrane region are essential for MmpL3 function and are most likely involved in this proton relay pathway. The mechanism and extent of TMM transport mediated by MmpL3 is still not fully understood. Spheroplasts assays have suggested that MmpL3 acts as a flippase [15]. This conclusion was derived from the accumulation of TMM in the inner leaflet of the plasma membrane after MmpL3 inhibition. Although this would point to MmpL3 acting as a flippase, there is the possibility that MmpL3 inhibition would affect also other proteins acting upstream in the transport pathway and/or TMM biosynthetic enzymes. This holds true for other MmpL transporters where disruption of the transport leads to the accumulation of biosynthetic precursors and, in some cases, the complete abolition of the synthesis of the substrate $[74,78,85,86]$.

The recently solved crystal structure of MmpL3 has shed some light as to the possible mechanism of TMM translocation $[25,87]$. Crystals of MmpL3 from M. smegmatis were diffracted to a 2.59 A resolution. Surprisingly, the $3 \mathrm{D}$ structure of this transporter is different from other RND transporters like AcrB, MexB, CusA, MtrD, CmeB and HpnN. The structure shows that the $N$-terminal and $C$-terminal halves are assembled in a twofold pseudo symmetrical fashion and the two periplasmic domains (PD1 and PD2) interact with each other and are also flexible. MmpL3 possesses a cavity that extends from the outer leaflet of the inner membrane up to the periplasmic domain. This cavity is large enough to fit a TMM molecule. Fortuitously, MmpL3 co-purified with n-dodecyl- $\beta$-D-maltoside (the detergent used for solubilization) and phosphatidylethanolamine (PE) bound to it. The former was found in the hydrophobic pocket created by TMs 7-10 while the latter was bound to the periplasmic domain within the large space between PD1 and PD2. These results reinforce the idea of MmpL3 channeling its substrate from the outer leaflet of the inner membrane up to the periplasmic space. The authors further demonstrated that TMM binds to purified MmpL3 with a $K_{d}$ of $3.7 \pm 1.3 \mu \mathrm{M}$ while there was no binding when TDM was assayed. In addition to PE and TMM, both phosphatidylglycerol and cardiolipin interacted with MmpL3. Whether these phospholipids act as substrates for MmpL3 in whole cells remains to be determined.

Native mass spectra, Small-angle X-ray scattering (SAXS) data and Blue-Native PAGE of the purified MmpL3 transporter indicate that it is a monomer in detergent solution [25,87]. It has to be noted that in both cases MmpL3 was purified devoid of the $C$-terminal domain due to its instability in solution and this domain was shown to be important for MmpL3 oligomerization [83]. This is in contrast to the quaternary structure of CmpL1, a Corynebacterium glutamicum ortholog, which has been shown to possess a trimeric quaternary structure [81]. There is a great variety of quaternary structures among the RND superfamily of transporters, while the efflux subfamily of RND transporters, namely, AcrB [88], MexB [89] and MtrD [90] exist as trimers, the hopanoid biosynthesis-associated transporter $(\mathrm{HpnN})$ from Burkholderia multivorans is a dimer [91] and human NPC1 is a monomer [92]. Due to this high variability, we cannot rule out that MmpL3 has a higher oligomerization state in native conditions found in the mycobacterial cell membrane.

\subsection{MmpL3: The Achilles Heel of Mycobacterium Tuberculosis}

In recent years, a diversity of scaffolds have been reported to inhibit MmpL3 (Table 2): SQ109 (diamine), DA5 (SQ109 related compound), BM212 (diarylpyrrole), Au1235 (adamantyl urea), C215 (benzimidazole), NITD-349 (indolecarboxamides), THP P (tetrathydropyrazolo pyrimidine), Spiro ( $N$-benzyl-6' $7^{\prime}$-dihydrospiro[piperidine-4,4'-thieno[3,2-c]pyrans]), PIPD1 (piperidinol), E11 (acetamide) and HC2091 (carboxamide) [36-38,51,93-97]. 
Table 2. Main MmpL3 inhibitors showing antitubercular activity.

\begin{tabular}{|c|c|c|c|c|}
\hline Chemical Class & Compound & Structure & M. tuberculosis MIC & Ref. \\
\hline Diarylpyrroles & BM212 & & $3.6 \mu \mathrm{M}$ & [36] \\
\hline & DA5 & & $9.97 \mu \mathrm{M}$ & [37] \\
\hline & SQ109 & & $0.78 \mu \mathrm{M}$ & [37] \\
\hline Adamantyl urea & AU1235 & & $0.3 \mu \mathrm{M}$ & [38] \\
\hline Benzimidazoles & $\mathrm{C} 215$ & & $16.0 \mu \mathrm{M}$ & [51] \\
\hline Indolcarboxamides & NIDT349 & & $0.023 \mu \mathrm{M}$ & [93] \\
\hline $\begin{array}{l}\text { Tetrahydropyrazolo } \\
\text { pyrimidine }\end{array}$ & THP P & & $0.3 \mu \mathrm{M}$ & [94] \\
\hline 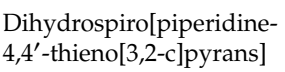 & Spiro & & $0.3 \mu \mathrm{M}$ & [94] \\
\hline Piperidinols & PIPD1 & & $1.28 \mu \mathrm{M}$ & [95] \\
\hline Acetamides & E11 & & $8.0 \mu \mathrm{M}$ & [96] \\
\hline Carboxamides & HC2091 & & $19.3 \mu \mathrm{M}$ & [97] \\
\hline
\end{tabular}

Among these compounds, SQ109 is the most advanced in the TB drug pipeline and has completed Phase I clinical trials in the US and Phase II clinical trials in Africa. SQ109 was identified originally from a combinatorial library screening based on the 1,2-ethylenediamine structure of ethambutol. However, other structural dissimilarities between SQ109 and ethambutol, the significant activity of SQ109 against drug-resistant strains of $M$. tuberculosis, including those that were ethambutol-resistant, suggested that SQ109 had a different target than its parent molecule [98]. SQ109 showed bactericidal activity against M. tuberculosis in vitro, including MDR and XDR-TB. Furthermore, it had activity against intracellular bacilli as well as an extremely low spontaneous resistance rate [37]. In addition to that, it showed synergistic activity with isoniazid and rifampicin and additive effects with streptomycin in vitro [99]. 
SQ109 also increases the activity of the new TB drug bedaquiline in vitro [100]. Replacement of ethambutol by SQ109 in the standard regimen in mice led to a $1.5 \mathrm{n} \log$ decrease in colony-forming units (CFUs) [101]. Furthermore, SQ109 was safe and well-tolerated in Phase I and Phase IIa clinical trials [102].

MmpL3 seems to be a promiscuous target since a plethora of compounds with dissimilar scaffolds have been shown to affect its activity and every new library screening seems to lead to novel scaffolds targeting the same enzyme. However, the reason for this extreme susceptibility is not clear. One possibility is that the compounds, due to their high hydrophobicity, get vastly enriched in the membrane where they can bind readily to MmpL3. This, in addition to the extreme vulnerability of MmpL3, would explain the variety of compounds targeting MmpL3.

There has been some controversy as to the direct or indirect inhibition of these compounds against MmpL3, it has been suggested that some compounds may act indirectly on MmpL3 by disrupting the $\mathrm{pH}$ gradient and/or membrane potential which will disrupt the proton relay needed by MmpL3 to pump out TMM. Indeed, while SQ109 and BM212 display a broad spectrum of activity and are active against non-replicating Mtb bacilli, some others specifically target mycobacteria and do not kill nonreplicating bacilli $[16,103,104]$. In order to solve this controversy and to shed more light on the mechanism of action of these inhibitors, Li et al. have recently developed assays both in vitro and in whole cells to identify direct inhibitors of MmpL3. Their use of fluorescent competition assays and surface plasmon resonance experiments with MmpL3 purified protein has shown that SQ109, BM212, Au1235, NITD304, NITD349 and THPP1 all bind to MmpL3. The authors also showed that only SQ109 and BM212 dissipated both $\Delta \mathrm{pH}$ and $\Delta \Psi$ (although the latter only at high concentrations). These assays could be a great tool for assessing the specificity of new and previously identified drugs that are believed to act against MmpL3 [105].

Recently, the crystal structure of M. smegmatis MmpL3 alone and in complex with four TB drug candidates has been solved [25]. Analysis of the transmembrane region has shown the existence of two pairs of hydrophilic residues (D256-Y646 and Y257-D645) on TM4 and TM 10 which links these two helices by forming hydrogen bonds. These residues are similar to the Asp-Asp-Lys triad found in AcrB and the Asp-Asp-Thr triad in SecDF, which are known to be involved in the proton relay pathway $[106,107]$. Consistently with this, three out of four of these residues have been shown to be essential for MmpL3 activity [81]. Furthermore, this catalytic tetrad is conserved in most MmpL transporters, with the exception of MmpL7, so it is likely that all MmpL transporters use the same mechanism to drive its substrate translocation [81].

The crystal structure of MmpL3 bound to SQ109, Au1235 and ICA38 has shown that these MmpL3 inhibitors bind to the same pocket in the center of the transmembrane region of the protein (Figure $3 \mathrm{~A}$ ), inducing conformational changes which in turn disrupt the interaction of the two Asp-Tyr pairs involved in proton translocation (Figure 3B,C). Furthermore, molecular docking assays with six other compounds (BM212, NITD-349, GSK2200150A, C215, PIPD1 and HC2091) showed that they can fit the same binding pocket within MmpL3. Thus, MmpL3 inhibitors seem to have an identical mechanism of action, binding to the same pocket and blocking the proton translocation relay pathway that is essential for substrate transport. This is also supported by the fact that the majority of resistance mutations found in MmpL3 lie in the TM region, close to the binding pocket. Zhang et al. purified 12 different mutant versions of MmpL3 and showed that most of the mutations affected the binding of the inhibitors to the pocket by disrupting hydrophobic/electrostatic interactions, inducing conformational changes or causing steric hindrance which leads to a decrease or abolition of the binding. On the other hand, there is still no clear evidence as to how mutations located further for the binding pocket induce resistance. Although MmpL3 is the only essential MmpL protein in M. tuberculosis, several other MmpL proteins have been shown to be required for virulence and/or drug efflux $[108,109]$. The fact that all inhibitors act by disrupting the proton relay pathway, a conserved feature of all MmpL transporters, opens the avenue for the development of molecules that target not only MmpL3 but all the MmpL family of transporters and thus affect virulence and resistance to other drugs. 

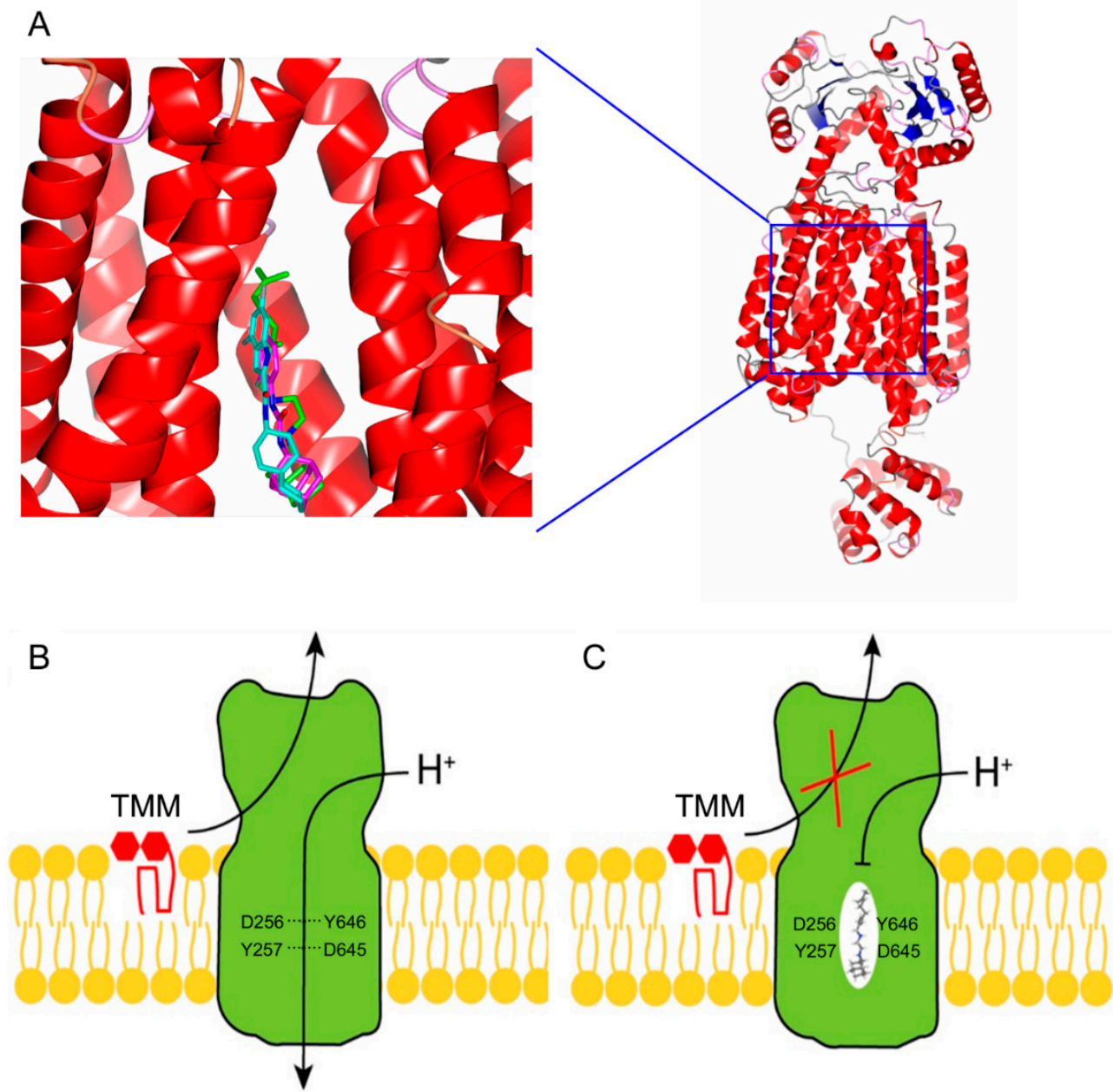

Figure 3. (A) Crystal structure of Mtb MmpL3 and detail of the inhibitors binding site (SQ109, PDB: 6AJG with carbon atoms in green; AU1235, PDB: 6AJH with carbon atoms in magenta; ICA38 PDB: 6AJJ with carbon atoms in cyan [25]). (B) Mechanism of transport of MmpL3: The flow of protons through charged residues in the transmembrane region of MmpL3 drives conformational changes that lead to the transport of TMM from the membrane to the periplasmic space. (C) MmpL3 inhibitors bind to a pocket in the transmembrane region of MmpL3, disrupting the electrostatic interactions between D256 and Y257 with Y646 and D645, respectively. This blocks the proton relay pathway and ultimately TMM translocation.

In summary, these findings will lead to a new era in MmpL3 inhibitor drug discovery since structure-guided molecules can now be designed with better anti-tubercular efficacy and pharmacokinetic/pharmacodynamic (PK/PD) properties.

\section{Future Perspectives for DprE1 and MmpL3 Inhibitors in Clinical Therapy}

Promiscuous targets could be an obstacle in the discovery of novel antitubercular drug targets, being recurrently found in HTS [110], nevertheless, they have been proven really useful for the development of novel drug candidates. This is well demonstrated by the fact that five compounds currently in clinical trials inhibit these targets, with DprE1 inhibitors TBA-7379, BTZ043 and Macozinone in Phase I, while the QcrB inhibitor Telacebec, the MmpL3 inhibitor SQ109 and again the Macozinone are in Phase II [26-29].

In particular, Macozinone has completed a dose-escalation phase I study in healthy male volunteers and a multiple ascending dose study in Russia, which demonstrated the good safety profile of the compound. Moreover, in 2018 it completed a Phase IIa Early Bactericidal Activity (EBA) study in 
Russia and Belarus in drug sensitive-TB (DS-TB) patients, confirming the safety and efficacy of the drug. In parallel, a Phase I clinical study has been initiated in Switzerland, by the nonprofit Innovative Medicines for Tuberculosis (iM4TB) foundation [24].

The MmpL3 inhibitor SQ109 has completed a Phase 2b study in Russia which demonstrated its efficacy in MDR-TB patients, with a good tolerability profile [111]. Furthermore, SQ109 was demonstrated to enhance the activity of isoniazid, rifampicin and bedaquiline and shortened clearance of TB in a mice model. The drug now has also completed three Phase I studies in the USA and two Phase II studies in Africa in DS-TB patients.

These studies thus demonstrate the great potential of these targets for the development of a new drug to reach the objective to eradicate TB.

Author Contributions: Conceptualization, G.R. and L.R.C.; writing, G.D., J.M.B. and L.R.C., review and editing, M.R.P., E.D.R., G.R. and L.R.C.; visualization, J.M.B. and L.R.C.; project administration, G.R. All authors have read and agreed to the published version of the manuscript.

Funding: This research was funded by the Italian Ministry of Education, University and Research (MIUR): Dipartimenti di Eccellenza Program (2018-2022)—Dept. of Biology and Biotechnology “L. Spallanzani", University of Pavia (G.D., M.R.P., E.D.R., G.R. and L.R.C.).

Conflicts of Interest: The authors declare no conflict of interest.

\section{References}

1. World Health Organization. Global Tuberculosis Report 2019. Available online: https://www.who.int/tb/ publications/global_report/en/ (accessed on 7 January 2020).

2. Lechartier, B.; Rybniker, J.; Zumla, A.; Cole, S.T. Tuberculosis drug discovery in the post-post-genomic era. EMBO Mol. Med. 2014, 6, 158-168. [CrossRef]

3. Chiarelli, L.R.; Mori, G.; Esposito, M.; Orena, B.S.; Pasca, M.R. New and old hot drug targets in tuberculosis. Curr. Med. Chem. 2016, 23, 3813-3846. [CrossRef]

4. Meneghetti, F.; Villa, S.; Gelain, A.; Barlocco, D.; Chiarelli, L.R.; Pasca, M.R.; Costantino, L. Iron acquisition pathways as targets for antitubercular drugs. Curr. Med. Chem. 2016, 23, 4009-4026. [CrossRef]

5. Mori, M.; Sammartino, J.C.; Costantino, L.; Gelain, A.; Meneghetti, F.; Villa, S.; Chiarelli, L.R. An Overview on the Potential Antimycobacterial Agents Targeting Serine/Threonine Protein Kinases from Mycobacterium tuberculosis. Curr. Top. Med. Chem. 2019, 19, 646-661. [CrossRef] [PubMed]

6. Andries, K.; Verhasselt, P.; Guillemont, J.; Göhlmann, H.W.; Neefs, J.M.; Winkler, H.; Van Gestel, J.; Timmerman, P.; Zhu, M.; Lee, E.; et al. A diarylquinoline drug active on the ATP synthase of Mycobacterium tuberculosis. Science 2005, 307, 223-227. [CrossRef] [PubMed]

7. Matsumoto, M.; Hashizume, H.; Tomishige, T.; Kawasaki, M.; Tsubouchi, H.; Sasaki, H.; Shimokawa, Y.; Komatsu, M. OPC-67683, a nitro-dihydro-imidazooxazole derivative with promising action against tuberculosis in vitro and in mice. PLoS Med. 2006, 3, e466. [CrossRef] [PubMed]

8. Stover, C.K.; Warrener, P.; VanDevanter, D.R.; Sherman, D.R.; Arain, T.M.; Langhorne, M.H.; Anderson, S.W.; Towell, J.A.; Yuan, Y.; McMurray, D.N.; et al. A small-molecule nitroimidazopyran drug candidate for the treatment of tuberculosis. Nature 2000, 405, 962-966. [CrossRef] [PubMed]

9. Ryan, N.J.; Lo, J.H. Delamanid: First global approval. Drugs 2014, 74, 1041-1045. [CrossRef] [PubMed]

10. Keam, S.J. Pretomanid: First Approval. Drugs 2019, 79, 1797-1803. [CrossRef]

11. Cole, S.T. Inhibiting Mycobacterium tuberculosis within and without. Philos. Trans. R. Soc. Lond. B Biol. Sci. 2016, 371, 20150506. [CrossRef]

12. Lee, B.S.; Pethe, K. Therapeutic potential of promiscuous targets in Mycobacterium tuberculosis. Curr. Opin. Pharmacol. 2018, 42, 22-26. [CrossRef] [PubMed]

13. Campaniço, A.; Moreira, R.; Lopes, F. Drug discovery in tuberculosis. New drug targets and antimycobacterial agents. Eur. J. Med. Chem. 2018, 150, 525-545. [CrossRef] [PubMed]

14. Mikusová, K.; Huang, H.; Yagi, T.; Holsters, M.; Vereecke, D.; D’Haeze, W.; Scherman, M.S.; Brennan, P.J.; McNeil, M.R.; Crick, D.C. Decaprenylphosphoryl arabinofuranose, the donor of the D-arabinofuranosyl residues of mycobacterial arabinan, is formed via a two-step epimerization of decaprenylphosphoryl ribose. J. Bacteriol. 2005, 187, 8020-8025. [CrossRef] [PubMed] 
15. Xu, Z.; Meshcheryakov, V.A.; Poce, G.; Chng, S.S. MmpL3 is the flippase for mycolic acids in mycobacteria. Proc. Natl. Acad. Sci. USA 2017, 114, 7993-7998. [CrossRef] [PubMed]

16. Li, W.; Upadhyay, A.; Fontes, F.L.; North, E.J.; Wang, Y.; Crans, D.C.; Grzegorzewicz, A.E.; Jones, V.; Franzblau, S.G.; Lee, R.E.; et al. Novel insights into the mechanism of inhibition of MmpL3, a target of multiple pharmacophores in Mycobacterium tuberculosis. Antimicrob. Agents Chemother. 2014, 58, 6413-6423. [CrossRef] [PubMed]

17. Abrahams, K.A.; Cox, J.A.; Spivey, V.L.; Loman, N.J.; Pallen, M.J.; Constantinidou, C.; Fernández, R.; Alemparte, C.; Remuiñán, M.J.; Barros, D.; et al. Identification of novel imidazo[1,2-a]pyridine inhibitors targeting M. tuberculosis QcrB. PLoS ONE 2012, 7, e52951. [CrossRef]

18. Pethe, K.; Bifani, P.; Jang, J.; Kang, S.; Park, S.; Ahn, S.; Jiricek, J.; Jung, J.; Jeon, H.K.; Cechetto, J.; et al. Discovery of Q203, a potent clinical candidate for the treatment of tuberculosis. Nat. Med. 2013, 19, 1157-1160. [CrossRef]

19. Wilson, R.; Kumar, P.; Parashar, V.; Vilchèze, C.; Veyron-Churlet, R.; Freundlich, J.S.; Barnes, S.W.; Walker, J.R.; Szymonifka, M.J.; Marchiano, E.; et al. Antituberculosis thiophenes define a requirement for Pks13 in mycolic acid biosynthesis. Nat. Chem. Biol. 2013, 9, 499-506. [CrossRef]

20. Aggarwal, A.; Parai, M.K.; Shetty, N.; Wallis, D.; Woolhiser, L.; Hastings, C.; Dutta, N.K.; Galaviz, S.; Dhakal, R.C.; Shrestha, R.; et al. Development of a Novel Lead that Targets M. tuberculosis Polyketide Synthase 13. Cell 2017, 170, 249-259. [CrossRef]

21. Grant, S.S.; Kawate, T.; Nag, P.P.; Silvis, M.R.; Gordon, K.; Stanley, S.A.; Kazyanskaya, E.; Nietupski, R.; Golas, A.; Fitzgerald, M.; et al. Identification of novel inhibitors of nonreplicating Mycobacterium tuberculosis using a carbon starvation model. ACS Chem. Biol. 2013, 8, 2224-2234. [CrossRef]

22. Bonnett, S.A.; Dennison, D.; Files, M.; Bajpai, A.; Parish, T. A class of hydrazones are active against non-replicating Mycobacterium tuberculosis. PLoS ONE 2018, 13, e0198059. [CrossRef] [PubMed]

23. Boldrin, F.; Degiacomi, G.; Serafini, A.; Kolly, G.S.; Ventura, M.; Sala, C.; Provvedi, R.; Palù, G.; Cole, S.T.; Manganelli, R. Promoter mutagenesis for fine-tuning expression of essential genes in Mycobacterium tuberculosis. Microb. Biotechnol. 2018, 11, 238-247. [CrossRef] [PubMed]

24. Lupien, A.; Vocat, A.; Foo, C.S.; Blattes, E.; Gillon, J.Y.; Makarov, V.; Cole, S.T. Optimized background regimen for treatment of active tuberculosis with the next-generation benzothiazinone Macozinone (PBTZ169). Antimicrob. Agents Chemother. 2018, 62, e00840-18. [CrossRef] [PubMed]

25. Zhang, B.; Li, J.; Yang, X.; Wu, L.; Zhang, J.; Yang, Y.; Zhao, Y.; Zhang, L.; Cheng, X.; Liu, Z.; et al. Crystal structures of membrane transporter MmpL3, an anti-TB drug target. Cell 2019, 176, 636-648. [CrossRef] [PubMed]

26. Available online: https://www.newtbdrugs.org/pipeline/compound/sq109 (accessed on 4 December 2019).

27. Available online: https://www.newtbdrugs.org/pipeline/compound/tba-7371 (accessed on 4 December 2019).

28. Available online: https://www.newtbdrugs.org/pipeline/trials/phase-2-telacebec-q203-eba (accessed on 4 December 2019).

29. Available online: https://www.newtbdrugs.org/pipeline/compound/macozinone-mcz-pbtz-169 (accessed on 4 December 2019).

30. Makarov, V.; Manina, G.; Mikusova, K.; Möllmann, U.; Ryabova, O.; Saint-Joanis, B.; Dhar, N.; Pasca, M.R.; Buroni, S.; Lucarelli, A.P.; et al. Benzothiazinones kill Mycobacterium tuberculosis by blocking arabinan synthesis. Science 2009, 324, 801-804. [CrossRef] [PubMed]

31. Wolucka, B.A. Biosynthesis of D-arabinose in mycobacteria-A novel bacterial pathway with implications for antimycobacterial therapy. FEBS J. 2008, 275, 2691-2711. [CrossRef]

32. Christophe, T.; Jackson, M.; Jeon, H.K.; Fenistein, D.; Contreras-Dominguez, M.; Kim, J.; Genovesio, A.; Carralot, J.P.; Ewann, F.; Kim, E.H.; et al. High content screening identifies decaprenyl-phosphoribose 2' epimerase as a target for intracellular antimycobacterial inhibitors. PLoS Pathog. 2009, 5, e1000645. [CrossRef]

33. Magnet, S.; Hartkoorn, R.C.; Székely, R.; Pató, J.; Triccas, J.A.; Schneider, P.; Szántai-Kis, C.; Orfi, L.; Chambon, M.; Banfi, D.; et al. Leads for antitubercular compounds from kinase inhibitor library screens. Tuberculosis 2010, 90, 354-360. [CrossRef]

34. Matsoso, L.G.; Kana, B.D.; Crellin, P.K.; Lea-Smith, D.J.; Pelosi, A.; Powell, D.; Dawes, S.S.; Rubin, H.; Coppel, R.L.; Mizrahi, V. Function of the cytochrome bc1-aa3 branch of the respiratory network in mycobacteria and network adaptation occurring in response to its disruption. J. Bacteriol. 2005, 187, 6300-6308. [CrossRef] 
35. Kolly, G.S.; Boldrin, F.; Sala, C.; Dhar, N.; Hartkoorn, R.C.; Ventura, M.; Serafini, A.; McKinney, J.D.; Manganelli, R.; Cole, S.T. Assessing the essentiality of the decaprenyl-phospho-d-arabinofuranose pathway in Mycobacterium tuberculosis using conditional mutants. Mol. Microbiol. 2014, 92, 194-211. [CrossRef]

36. La Rosa, V.; Poce, G.; Canseco, J.O.; Buroni, S.; Pasca, M.R.; Biava, M.; Raju, R.M.; Porretta, G.C.; Alfonso, S.; Battilocchio, C.; et al. MmpL3 is the cellular target of the antitubercular pyrrole derivative BM212. Antimicrob. Agents Chemother. 2012, 56, 324-331. [CrossRef] [PubMed]

37. Tahlan, K.; Wilson, R.; Kastrinsky, D.B.; Arora, K.; Nair, V.; Fischer, E.; Barnes, S.W.; Walker, J.R.; Alland, D.; Barry, C.E.; et al. SQ109 targets MmpL3, a membrane transporter of trehalose monomycolate involved in mycolic acid donation to the cell wall core of Mycobacterium tuberculosis. Antimicrob. Agents Chemother. 2012, 56, 1797-1809. [CrossRef] [PubMed]

38. Grzegorzewicz, A.E.; Pham, H.; Gundi, V.A.; Scherman, M.S.; North, E.J.; Hess, T.; Jones, V.; Gruppo, V.; Born, S.E.; Korduláková, J.; et al. Inhibition of mycolic acid transport across the Mycobacterium tuberculosis plasma membrane. Nat. Chem. Biol. 2012, 8, 334-341. [CrossRef]

39. Degiacomi, G.; Benjak, A.; Madacki, J.; Boldrin, F.; Provvedi, R.; Palù, G.; Kordulakova, J.; Cole, S.T.; Manganelli, R. Essentiality of mmpL3 and impact of its silencing on Mycobacterium tuberculosis gene expression. Sci. Rep. 2017, 7, 43495. [CrossRef] [PubMed]

40. Riccardi, G.; Pasca, M.R.; Chiarelli, L.R.; Manina, G.; Mattevi, A.; Binda, C. The DprE1 enzyme, one of the most vulnerable targets of Mycobacterium tuberculosis. Appl. Microbiol. Biotechnol. 2013, 97, 8841-8848. [CrossRef]

41. Neres, J.; Pojer, F.; Molteni, E.; Chiarelli, L.R.; Dhar, N.; Boy-Rottger, S.; Buroni, S.; Fullam, E.; Degiacomi, G.; Lucarelli, A.P.; et al. Structural basis for benzothiazinone-mediated killing of Mycobacterium tuberculosis. Sci. Trans. Med. 2012, 4, 150ra121. [CrossRef]

42. Batt, S.M.; Cacho Izquierdo, M.; Castro Pichel, J.; Stubbs, C.J.; Del Peral, L.V.-G.; Pérez-Herrán, E.; Dhar, N.; Mouzon, B.; Rees, M.; Hutchinson, J.P.; et al. Whole cell target engagement identifies novel inhibitors of Mycobacterium tuberculosis decaprenylphosphoryl- $\beta$-D-ribose oxidase. ACS Infect. Dis 2015, 1, 615-626. [CrossRef]

43. Batt, S.M.; Jabeen, T.; Bhowruth, V.; Quill, L.; Lund, P.A.; Eggeling, L.; Alderwick, L.J.; Fütterer, K.; Besra, G.S. Structural basis of inhibition of Mycobacterium tuberculosis DprE1 by benzothiazinone inhibitors. Proc. Natl. Acad. Sci. USA 2012, 109, 11354-11359. [CrossRef]

44. Landge, S.; Mullick, A.B.; Nagalapur, K.; Neres, J.; Subbulakshmi, V.; Murugan, K.; Ghosh, A.; Sadler, C.; Fellows, M.D.; Humnabadkar, V.; et al. Discovery of benzothiazoles as antimycobacterial agents: Synthesis, structure-activity relationships and binding studies with Mycobacterium tuberculosis decaprenylphosphoryl- $\beta$-D-ribose 2'-oxidase. Bioorg. Med. Chem. 2015, 23, 7694-7710. [CrossRef]

45. Piton, J.; Foo, C.S.; Cole, S.T. Structural studies of Mycobacterium tuberculosis DprE1 interacting with its inhibitors. Drug Discov. Today 2017, 22, 526-533. [CrossRef]

46. Chikhale, R.V.; Barmade, M.A.; Murumkar, P.R.; Yadav, M.R. Overview of the development of dpre1 inhibitors for combating the menace of tuberculosis. J. Med. Chem. 2018, 61, 8563-8593. [CrossRef] [PubMed]

47. Mori, G.; Chiarelli, L.R.; Riccardi, G.; Pasca, M.R. New prodrugs against tuberculosis. Drug Discov. Today 2017, 22, 519-525. [CrossRef] [PubMed]

48. Trefzer, C.; Škovierová, H.; Buroni, S.; Bobovská, A.; Nenci, S.; Molteni, E.; Pojer, F.; Pasca, M.R.; Makarov, V.; Cole, S.T.; et al. Benzothiazinones are suicide inhibitors of mycobacterial decaprenylphosphoryl- $\beta$-D-ribofuranose 2'-oxidase DprE1. J. Am. Chem. Soc. 2012, 134, 912-915. [CrossRef] [PubMed]

49. Makarov, V.; Lechartier, B.; Zhang, M.; Neres, J.; van der Sar, A.M.; Raadsen, S.A.; Hartkoorn, R.C.; Ryabova, O.B.; Vocat, A.; Decosterd, L.A.; et al. Towards a new combination therapy for tuberculosis with next generation benzothiazinones. EMBO Mol. Med. 2014, 6, 372-383. [CrossRef]

50. Richter, A.; Rudolph, I.; Möllmann, U.; Voigt, K.; Chung, C.W.; Singh, O.M.P.; Rees, M.; Mendoza-Losana, A.; Bates, R.; Ballell, L.; et al. Novel insight into the reaction of nitro, nitroso and hydroxylamino benzothiazinones and of benzoxacinones with Mycobacterium tuberculosis DprE1. Sci. Rep. 2018, 8, 13473. [CrossRef]

51. Stanley, S.A.; Grant, S.S.; Kawate, T.; Iwase, N.; Shimizu, M.; Wivagg, C.; Silvis, M.; Kazyanskaya, E.; Aquadro, J.; Golas, A.; et al. Identification of novel inhibitors of M. tuberculosis growth using whole cell based high-throughput screening. ACS Chem. Biol. 2012, 7, 1377-1384. [CrossRef] 
52. De Jesus Lopes Ribeiro, A.L.; Degiacomi, G.; Ewann, F.; Buroni, S.; Incandela, M.L.; Chiarelli, L.R.; Mori, G.; Kim, J.; Contreras-Dominguez, M.; Park, Y.-S.; et al. Analogous mechanisms of resistance to benzothiazinones and dinitrobenzamides in Mycobacterium smegmatis. PLoS ONE 2011, 6, e26675. [CrossRef]

53. Li, H.; Jogl, G. Crystal structure of decaprenylphosphoryl- $\beta$-D-ribose 2 '-epimerase from Mycobacterium smegmatis. Proteins 2013, 81, 538-543. [CrossRef]

54. Landge, S.; Ramachandran, V.; Kumar, A.; Neres, J.; Murugan, K.; Sadler, C.; Fellows, M.D.; Humnabadkar, V.; Vachaspati, P.; Raichurkar, A.; et al. Nitroarenes as antitubercular agents: Stereoelectronic modulation to mitigate mutagenicity. ChemMedChem 2016, 11, 331-339. [CrossRef]

55. Wang, F.; Sambandan, D.; Halder, R.; Wang, J.; Batt, S.M.; Weinrick, B.; Ahmad, I.; Yang, P.; Zhang, Y.; Kim, J.; et al. Identification of a small molecule with activity against drug-resistant and persistent tuberculosis. Proc. Natl. Acad. Sci. USA 2013, 110, E2510-E2517. [CrossRef]

56. Liu, R.; Lyu, X.; Batt, S.M.; Hsu, M.H.; Harbut, M.B.; Vilchèze, C.; Cheng, B.; Ajayi, K.; Yang, B.; Yang, Y.; et al. Determinants of the inhibition of DprE1 and CYP2C9 by antitubercular thiophenes. Angew. Chem. Int. Ed. Engl. 2017, 56, 13011-13015. [CrossRef] [PubMed]

57. Piton, J.; Vocat, A.; Lupien, A.; Foo, C.S.; Riabova, O.; Makarov, V.; Cole, S.T. Structure-based drug design and characterization of sulfonyl-piperazine benzothiazinone inhibitors of DprE1 from Mycobacterium tuberculosis. Antimicrob. Agents Chemother. 2018, 62, e00681-18. [CrossRef] [PubMed]

58. Neres, J.; Hartkoorn, R.C.; Chiarelli, L.R.; Gadupudi, R.; Pasca, M.R.; Mori, G.; Venturelli, A.; Savina, S.; Makarov, V.; Kolly, G.S.; et al. 2-carboxyquinoxalines kill Mycobacterium tuberculosis through noncovalent inhibition of DprE1. ACS Chem. Biol. 2015, 10, 705-714. [CrossRef] [PubMed]

59. Abrahams, K.A.; Besra, G.S. Mycobacterial cell wall biosynthesis: A multifaceted antibiotic target. Parasitology 2018, 145, 116-133. [CrossRef] [PubMed]

60. Brecik, M.; Centárová, I.; Mukherjee, R.; Kolly, G.S.; Huszár, S.; Bobovská, A.; Kilacsková, E.; Mokošová, V.; Svetlíková, Z.; Šarkan, M.; et al. DprE1 is a vulnerable tuberculosis drug target due to its cell wall localization. ACS Chem. Biol. 2015, 10, 1631-1636. [CrossRef] [PubMed]

61. Chikhale, R.; Menghani, S.; Babu, R.; Bansode, R.; Bhargavi, G.; Karodia, N.; Rajasekharan, M.V.; Paradkar, A.; Khedekar, P. Development of selective DprE1 inhibitors: Design, synthesis, crystal structure and antitubercular activity of benzothiazolylpyrimidine-5-carboxamides. Eur. J. Med. Chem. 2015, 96, 30-46. [CrossRef]

62. Naik, M.; Humnabadkar, V.; Tantry, S.J.; Panda, M.; Narayan, A.; Guptha, S.; Panduga, V.; Manjrekar, P.; Jena, L.K.; Koushik, K.; et al. 4-Aminoquinolone piperidine amides: Noncovalent inhibitors of DprE1 with long residence time and potent antimycobacterial activity. J. Med. Chem. 2014, 57, 5419-5434. [CrossRef]

63. Panda, M.; Ramachandran, S.; Ramachandran, V.; Shirude, P.S.; Humnabadkar, V.; Nagalapur, K.; Sharma, S.; Kaur, P.; Guptha, S.; Narayan, A.; et al. Discovery of pyrazolopyridones as a novel class of noncovalent DprE1 inhibitor with potent anti-mycobacterial activity. J. Med. Chem. 2014, 57, 4761-4771. [CrossRef]

64. Chatterji, M.; Shandil, R.; Manjunatha, M.R.; Solapure, S.; Ramachandran, V.; Kumar, N.; Saralaya, R.; Panduga, V.; Reddy, J.; Prabhakar, K.R.; et al. 1,4-azaindole, a potential drug candidate for treatment of tuberculosis. Antimicrob. Agents Chemother. 2014, 58, 5325-5331. [CrossRef]

65. Tiwari, R.; Moraski, G.C.; Krchňák, V.; Miller, P.A.; Colon-Martinez, M.; Herrero, E.; Oliver, A.G.; Miller, M.J. Thiolates chemically induce redox activation of BTZ043 and related potent nitroaromatic anti-tuberculosis agents. J. Am. Chem. Soc. 2013, 135, 3539-3549. [CrossRef]

66. Manina, G.; Bellinzoni, M.; Pasca, M.R.; Neres, J.; Milano, A.; De Jesus Lopes Ribeiro, A.L.; Buroni, S.; Skovierová, H.; Dianišková, P.; Mikušová, K.; et al. Biological and structural characterization of the Mycobacterium smegmatis nitroreductase $\mathrm{NfnB}$, and its role in benzothiazinone resistance. Mol. Microbiol. 2010, 77, 1172-1185. [CrossRef] [PubMed]

67. Makarov, V.; Neres, J.; Hartkoorn, R.C.; Ryabova, O.B.; Kazakova, E.; Šarkan, M.; Huszár, S.; Piton, J.; Kolly, G.S.; Vocat, A.; et al. The 8-Pyrrole-Benzothiazinones Are Noncovalent Inhibitors of DprE1 from Mycobacterium tuberculosis. Antimicrob. Agents Chemother. 2015, 59, 4446-4452. [CrossRef] [PubMed]

68. Tiwari, R.; Miller, P.A.; Chiarelli, L.R.; Mori, G.; Šarkan, M.; Centárová, I.; Cho, S.; Mikusová, K.; Franzblau, S.G.; Oliver, A.G.; et al. Design, syntheses, and anti-tb activity of 1,3-benzothiazinone azide and click chemistry products inspired by BTZ043. ACS Med. Chem. Lett. 2016, 7, 266-270. [CrossRef] [PubMed] 
69. Shirude, P.S.; Shandil, R.; Sadler, C.; Naik, M.; Hosagrahara, V.; Hameed, S.; Shinde, V.; Bathula, C.; Humnabadkar, V.; Kumar, N.; et al. Azaindoles: Noncovalent DprE1 inhibitors from scaffold morphing efforts, kill Mycobacterium tuberculosis and are efficacious in vivo. J. Med. Chem. 2013, 56, 9701-9708. [CrossRef]

70. Shirude, P.S.; Shandil, R.K.; Manjunatha, M.R.; Sadler, C.; Panda, M.; Panduga, V.; Reddy, J.; Saralaya, R.; Nanduri, R.; Ambady, A.; et al. Lead optimization of 1,4-azaindoles as antimycobacterial agents. J. Med. Chem. 2014, 57, 5728-5737. [CrossRef]

71. Jankute, M.; Byng, C.V.; Alderwick, L.J.; Besra, G.S. Elucidation of a protein-protein interaction network involved in Corynebacterium glutamicum cell wall biosynthesis as determined by bacterial two-hybrid analysis. Glycoconj. J. 2014, 31, 475-483. [CrossRef]

72. Bhutani, I.; Loharch, S.; Gupta, P.; Madathil, R.; Parkesh, R. Structure, dynamics, and interaction of Mycobacterium tuberculosis (Mtb) DprE1 and DprE2 examined by molecular modeling, simulation, and electrostatic studies. PLoS ONE 2015, 10, e0119771. [CrossRef]

73. Gawad, J.; Bonde, C. Decaprenyl-phosphoryl-ribose 2'-epimerase (DprE1): Challenging target for antitubercular drug discovery. Chem. Cent. J. 2018, 12, 72. [CrossRef]

74. Camacho, L.R.; Constant, P.; Raynaud, C.; Laneelle, M.A.; Triccas, J.A.; Gicquel, B.; Daffe, M.; Guilhot, C. Analysis of the phthiocerol dimycocerosate locus of Mycobacterium tuberculosis. Evidence that this lipid is involved in the cell wall permeability barrier. J. Biol. Chem. 2001, 276, 19845-19854. [CrossRef]

75. Converse, S.E.; Mougous, J.D.; Leavell, M.D.; Leary, J.A.; Bertozzi, C.R.; Cox, J.S. MmpL8 is required for sulfolipid-1 biosynthesis and Mycobacterium tuberculosis virulence. Proc. Natl. Acad. Sci. USA 2003, 100, 6121-6126. [CrossRef]

76. Pacheco, S.A.; Hsu, F.F.; Powers, K.M.; Purdy, G.E. MmpL11 protein transports mycolic acid-containing lipids to the mycobacterial cell wall and contributes to biofilm formation in Mycobacterium smegmatis. J. Biol. Chem. 2013, 288, 24213-24222. [CrossRef] [PubMed]

77. Wells, R.M.; Jones, C.M.; Xi, Z.; Speer, A.; Danilchanka, O.; Doornbos, K.S.; Sun, P.; Wu, F.; Tian, C.; Niederweis, M. Discovery of a siderophore export system essential for virulence of Mycobacterium tuberculosis. PLoS Pathog. 2013, 9, e1003120. [CrossRef] [PubMed]

78. Belardinelli, J.M.; Larrouy-Maumus, G.; Jones, V.; de Carvalho, L.P.S.; McNeil, M.R.; Jackson, M. Biosynthesis and translocation of unsulfated acyltrehaloses in Mycobacterium tuberculosis. J. Biol. Chem. 2014, 289, 27952-27965. [CrossRef] [PubMed]

79. Domenech, P.; Reed, M.B.; Barry, C.E. Contribution of the Mycobacterium tuberculosis MmpL protein family to virulence and drug resistance. Infect. Immun. 2005, 73, 3492-3501. [CrossRef]

80. Li, W.; Obregón-Henao, A.; Wallach, J.B.; North, E.J.; Lee, R.E.; Gonzalez-Juarrero, M.; Schnappinger, D.; Jackson, M. Therapeutic potential of the Mycobacterium tuberculosis mycolic acid transporter, MmpL3. Antimicrob. Agents Chemother. 2016, 60, 5198-5207. [CrossRef]

81. Belardinelli, J.M.; Yazidi, A.; Yang, L.; Fabre, L.; Li, W.; Jacques, B.; Angala, S.K.; Rouiller, I.; Zgurskaya, H.I.; Sygusch, J.; et al. Structure-function profile of MmpL3, the essential mycolic acid transporter from Mycobacterium tuberculosis. ACS Infect. Dis. 2016, 2, 702-713. [CrossRef]

82. Carel, C.; Nukdee, K.; Cantaloube, S.; Bonne, M.; Diagne, C.T.; Laval, F.; Daffé, M.; Zerbib, D. Mycobacterium tuberculosis proteins involved in mycolic acid synthesis and transport localize dynamically to the old growing pole and septum. PLoS ONE 2014, 9, e97148. [CrossRef]

83. Belardinelli, J.M.; Stevens, C.M.; Li, W.; Tan, Y.Z.; Jones, V.; Mancia, F.; Zgurskaya, H.I.; Jackson, M. The MmpL3 interactome reveals a complex crosstalk between cell envelope biosynthesis and cell elongation and division in mycobacteria. Sci. Rep. 2019, 9, 10728. [CrossRef]

84. Vilchèze, C.; Jacobs, W.R. The mechanism of isoniazid killing: Clarity through the scope of genetics. Annu. Rev. Microbiol. 2007, 61, 35-50. [CrossRef]

85. Medjahed, H.; Reyrat, J.M. Construction of Mycobacterium abscessus defined glycopeptidolipid mutants: Comparison of genetic tools. Appl. Environ. Microbiol. 2009, 75, 1331-1338. [CrossRef]

86. Seeliger, J.C.; Holsclaw, C.M.; Schelle, M.W.; Botyanszki, Z.; Gilmore, S.A.; Tully, S.E.; Niederweis, M.; Cravatt, B.F.; Leary, J.A.; Bertozzi, C.R. Elucidation and chemical modulation of sulfolipid-1 biosynthesis in Mycobacterium tuberculosis. J. Biol. Chem. 2012, 287, 7990-8000. [CrossRef] [PubMed] 
87. Su, C.C.; Klenotic, P.A.; Bolla, J.R.; Purdy, G.E.; Robinson, C.V.; Yu, E.W. MmpL3 is a lipid transporter that binds trehalose monomycolate and phosphatidylethanolamine. Proc. Natl. Acad. Sci. USA 2019, 116, 11241-11246. [CrossRef] [PubMed]

88. Murakami, S.; Nakashima, R.; Yamashita, E.; Yamaguchi, A. Crystal structure of bacterial multidrug efflux transporter AcrB. Nature 2002, 419, 587-593. [CrossRef]

89. Sennhauser, G.; Bukowska, M.A.; Briand, C.; Grütter, M.G. Crystal structure of the multidrug exporter MexB from Pseudomonas aeruginosa. J. Mol. Biol. 2009, 389, 134-145. [CrossRef] [PubMed]

90. Bolla, J.R.; Su, C.C.; Do, S.V.; Radhakrishnan, A.; Kumar, N.; Long, F.; Chou, T.H.; Delmar, J.A.; Lei, H.T.; Rajashankar, K.R.; et al. Crystal structure of the Neisseria gonorrhoeae MtrD inner membrane multidrug efflux pump. PLoS ONE 2014, 9, e97903. [CrossRef] [PubMed]

91. Kumar, N.; Su, C.C.; Chou, T.H.; Radhakrishnan, A.; Delmar, J.A.; Rajashankar, K.R.; Yu, E.W. Crystal structures of the Burkholderia multivorans hopanoid transporter HpnN. Proc. Natl. Acad. Sci. USA 2017, 114, 6557-6562. [CrossRef]

92. Gong, X.; Qian, H.; Zhou, X.; Wu, J.; Wan, T.; Cao, P.; Huang, W.; Zhao, X.; Wang, X.; Wang, P.; et al. Structural insights into the Niemann-Pick C1 (NPC1)-mediated cholesterol transfer and ebola infection. Cell 2016, 165, 1467-1478. [CrossRef]

93. Rao, S.P.; Lakshminarayana, S.B.; Kondreddi, R.R.; Herve, M.; Camacho, L.R.; Bifani, P.; Kalapala, S.K.; Jiricek, J.; Ma, N.L.; Tan, B.H.; et al. Indolcarboxamide is a preclinical candidate for treating multidrug-resistant tuberculosis. Sci. Transl. Med. 2013, 5, 214ra168. [CrossRef]

94. Remuiñán, M.J.; Pérez-Herrán, E.; Rullás, J.; Alemparte, C.; Martínez-Hoyos, M.; Dow, D.J.; Afari, J.; Mehta, N.; Esquivias, J.; Jiménez, E.; et al. Tetrahydropyrazolo[1,5-a]pyrimidine-3-carboxamide and $N$-benzyl-6' $7^{\prime}$-dihydrospiro[piperidine-4, $4^{\prime}$-thieno[3,2-c]pyran] analogues with bactericidal efficacy against Mycobacterium tuberculosis targeting MmpL3. PLoS ONE 2013, 8, e60933. [CrossRef]

95. Dupont, C.; Viljoen, A.; Dubar, F.; Blaise, M.; Bernut, A.; Pawlik, A.; Bouchier, C.; Brosch, R.; Guérardel, Y.; Lelièvre, J.; et al. A new piperidinol derivative targeting mycolic acid transport in Mycobacterium abscessus. Mol. Microbiol. 2016, 101, 515-529. [CrossRef]

96. Shetty, A.; Xu, Z.; Lakshmanan, U.; Hill, J.; Choong, M.L.; Chng, S.S.; Yamada, Y.; Poulsen, A.; Dick, T.; Gengenbacher, M. Novel acetamide indirectly targets mycobacterial transporter MmpL3 by proton motive force disruption. Front. Microbiol. 2018, 9, 2960. [CrossRef] [PubMed]

97. Zheng, H.; Williams, J.T.; Coulson, G.B.; Haiderer, E.R.; Abramovitch, R.B. HC2091 Kills Mycobacterium tuberculosis by targeting the MmpL3 mycolic acid transporter. Antimicrob. Agents Chemother. 2018, 62, e02459-17. [CrossRef] [PubMed]

98. Protopopova, M.; Hanrahan, C.; Nikonenko, B.; Samala, R.; Chen, P.; Gearhart, J.; Einck, L.; Nacy, C.A. Identification of a new antitubercular drug candidate, SQ109, from a combinatorial library of 1,2-ethylenediamines. J. Antimicrob. Chemother. 2005, 56, 968-974. [CrossRef] [PubMed]

99. Chen, P.; Gearhart, J.; Protopopova, M.; Einck, L.; Nacy, C.A. Synergistic interactions of SQ109, a new ethylene diamine, with front-line antitubercular drugs in vitro. J. Antimicrob. Chemother. 2006, 58, 332-337. [CrossRef] [PubMed]

100. Reddy, V.M.; Einck, L.; Andries, K.; Nacy, C.A. In vitro interactions between new antitubercular drug candidates SQ109 and TMC207. Antimicrob. Agents Chemother. 2010, 54, 2840-2846. [CrossRef] [PubMed]

101. Nikonenko, B.V.; Protopopova, M.; Samala, R.; Einck, L.; Nacy, C.A. Drug therapy of experimental tuberculosis (TB): Improved outcome by combining SQ109, a new diamine antibiotic, with existing TB drugs. Antimicrob. Agents Chemother. 2007, 51, 1563-1565. [CrossRef]

102. Heinrich, N.; Dawson, R.; du Bois, J.; Narunsky, K.; Horwith, G.; Phipps, A.J.; Nacy, C.A.; Aarnoutse, R.E.; Boeree, M.J.; Gillespie, S.H.; et al. Early phase evaluation of SQ109 alone and in combination with rifampicin in pulmonary TB patients. J. Antimicrob. Chemother. 2015, 70, 1558-1566. [CrossRef]

103. Veiga-Santos, P.; Li, K.; Lameira, L.; de Carvalho, T.M.; Huang, G.; Galizzi, M.; Shang, N.; Li, Q.; Gonzalez-Pacanowska, D.; Hernandez-Rodriguez, V.; et al. SQ109, a new drug lead for Chagas disease. Antimicrob. Agents Chemother. 2015, 59, 1950-1961. [CrossRef]

104. García-García, V.; Oldfield, E.; Benaim, G. Inhibition of Leishmania mexicana growth by the tuberculosis drug SQ109. Antimicrob. Agents Chemother. 2016, 60, 6386-6389. [CrossRef] 
105. Li, W.; Stevens, C.M.; Pandya, A.N.; Darzynkiewicz, Z.; Bhattarai, P.; Tong, W.; Gonzalez-Juarrero, M.; North, E.J.; Zgurskaya, H.I.; Jackson, M. Direct inhibition of MmpL3 by novel antitubercular compounds. ACS Infect. Dis. 2019, 5, 1001-1012. [CrossRef]

106. Seeger, M.A.; Diederichs, K.; Eicher, T.; Brandstätter, L.; Schiefner, A.; Verrey, F.; Pos, K.M. The AcrB efflux pump: Conformational cycling and peristalsis lead to multidrug resistance. Curr. Drug Targets 2008, 9, 729-749. [CrossRef]

107. Tsukazaki, T.; Mori, H.; Echizen, Y.; Ishitani, R.; Fukai, S.; Tanaka, T.; Perederina, A.; Vassylyev, D.G.; Kohno, T.; Maturana, A.D.; et al. Structure and function of a membrane component SecDF that enhances protein export. Nature 2011, 474, 235-238. [CrossRef] [PubMed]

108. Lamichhane, G.; Tyagi, S.; Bishai, W.R. Designer arrays for defined mutant analysis to detect genes essential for survival of Mycobacterium tuberculosis in mouse lungs. Infect. Immun. 2005, 73, 2533-2540. [CrossRef] [PubMed]

109. Hartkoorn, R.C.; Uplekar, S.; Cole, S.T. Cross-resistance between clofazimine and bedaquiline through upregulation of MmpL5 in Mycobacterium tuberculosis. Antimicrob. Agents Chemother. 2014, 58, 2979-2981. [CrossRef]

110. Oh, S.; Park, Y.; Engelhart, C.A.; Wallach, J.B.; Schnappinger, D.; Arora, K.; Manikkam, M.; Gac, B.; Wang, H.; Murgolo, N.; et al. Discovery and structure-activity-relationship study of N-Alkyl-5-hydroxypyrimidinone carboxamides as novel antitubercular agents targeting decaprenylphosphoryl- $\beta$-D-ribose 2'-oxidase. J. Med. Chem. 2018, 61, 9952-9965. [CrossRef] [PubMed]

111. Borisov, S.E.; Bogorodskaya, E.M.; Volchenkov, G.V.; Kulchavenya, E.V.; Maryandyshev, A.O.; Skornyakov, S.N.; Talibov, O.B.; Tikhonov, A.M.; Vasilyeva, I.A. Efficiency and safety of chemotherapy regimen with SQ109 in those suffering from multiple drug resistant tuberculosis. Tuberc. Lung Dis. 2018, 96, 6-18. [CrossRef]

(C) 2020 by the authors. Licensee MDPI, Basel, Switzerland. This article is an open access article distributed under the terms and conditions of the Creative Commons Attribution (CC BY) license (http://creativecommons.org/licenses/by/4.0/). 